\title{
Experimental Investigation of Dynamic Error for Manipulator Output Link During Its Motion Path Tryout
}

\author{
Yulia Zubkova, Yury Turygin * \\ Kalashnikov Izhevsk State Technical University, 7 Studencheskaya str., Izhevsk, Russia
}

\begin{abstract}
The paper considers the procedure of carrying out the experimental investigations of the dynamic component of the error for the manipulator output link based on empiric relations obtained experimentally. Results of experimental investigations are presented; they include the empiric relation of evaluating the dynamic characteristics of the manipulator during the tryout of the arbitrary spatial path.
\end{abstract}

Keywords: Positioning, accuracy, manipulator, mechatronic module of motion, dynamic error, experiment.

\section{Introduction}

In modern state of production a great attention is paid to increasing the quality of responsible and heavy loaded units obtained by cutting, overlaying, painting and welding, including the electron-beam welding (EBW). Such units found their application in many industrial branches, for instance, in rocket and ship engineering, nuclear engineering, power engineering, device and relay production, air-engine and automobile industry. It is stipulated by increased demands to the service life of such units and their operation reliability, to lowering the production cost and the cost of technique for robot-controlled systems (RCS). These demands are closely related to the positioning accuracy for mechatronic modules of motion (MMM) as components of RCS manipulators. Even greater attention is paid now to implementing the working function by MMM, for example, tryout of a certain motion path by a manipulator operating unit with the assigned accuracy of positioning. The term "positioning" here means aiming and transmitting the output link of the operating unit along the assigned motion path.

When thermal, mechanical or other deformations of the unit are essential within the manufacturing process or when it is necessary to obtain high positioning accuracy, it is required to control the position of the manipulator output link based on determining the positioning error during the tryout of the manipulator motion path. It is especially essential when velocities of manipulator displacement and/or the mass of the operating unit are considerable. Results of experiments carried out on the basis of the developed procedure of investigating the dynamic component of the error for the manipulator output link allow evaluating the dynamic characteristics of the manipulator during the tryout of the arbitrary spatial path.

\section{Three-cylinder Pneumatic Press with Electric Control}

Influenced by dynamic loads, there is a certain deformation of motion transducers 
for the operating unit and, therefore, displacement of the actual position for the manipulator output link with respect to the assigned position takes place. Dynamic forces imply here inertia forces when speeding up the operation unit, forces provided by the manufacturing process (if present), and friction forces in slideways. These forces are usually neglected due to their insignificant influence on the position of the operating unit [1, 2].

The existing method of approximated analysis of dynamic errors for robots presented in [2] is applied in cases when program motion paths are smooth and program motions are slow. In individual cases it is necessary to perform calculations by discrete time intervals to correct the position of the output link during the motion path tryout [1, 2].

However, taking into account the complexity of creating the dynamic models for multi-link manipulators of the welding gun and the blank displacement unit, an attempt was made to obtain empiric relations for variation of manipulator output link displacement depending on the obtained values of kinetic energy as

$$
\Delta_{d y n}=\mathrm{f}\left(T_{i}\right)
$$

where: $\Delta_{d y n}$ is the manipulator error related to its dynamic characteristics at considered points of the motion path $i ; T$ is the total kinetic energy of the mechanical system.

Here

$$
T=T_{a}+T_{o p},
$$

where: $T_{a}, T_{o p}$ is the kinetic energy of the manipulator and the operating unit.

The dynamic model of the manipulator can be developed based on Lagrange equation of the second kind for a holonomic system with $n$ degrees of freedom which can be presented as

$$
T_{i}=\frac{1}{2} \sum_{i=1}^{n}\left[\begin{array}{l}
m_{i}\left(v_{0 i x \mathrm{c}}^{2}+v_{0 i y \mathrm{c}}^{2}+v_{0 i z \mathrm{c}}^{2}\right) \\
+\left(J_{x_{i}} \varpi_{i x}^{2}+J_{y_{i}} \varpi_{i y}^{2}+J_{z_{i}} \varpi_{i z}^{2}\right)
\end{array}\right]
$$

where: $m_{i}$ is the mass of the link $i_{i} v_{0 i}$ is the velocity of a certain point of the link $O_{i}$ accepted to be the pole; $r_{i c}$ is the radius vector of the center of the link inertia in the system of related coordinates, the center of the coordinate system coinciding with the pole $O_{i} ; J_{i}$ is the inertia moment of the link $i_{\text {; }}$ $\omega_{i}$ is the vector of the angular velocity of the link in the accepted coordinate system.

When performing the experimental investigation for the dynamic component of the manipulator output link error, the investigated factors were the maximum linear velocity of the robot output link $v_{\max }$ at testing and automatic modes and the load mass $m$. Experiments were performed with the robot-manipulator with floor fixation produced by the company KUKA. The laser sensor of linear displacements ZX2-LDA (OMRON company) with measurement accuracy $0.0001 \mathrm{~mm}$ was chosen to be the external measuring device. The scheme of the experimental stand and the procedure of investigations are described in [3,4].

Having determined the values of kinetic energy $T_{i}$ at reference points of the motion path according to $(2,3)$ and having analyzed the experimental data, empirical relations were obtained for variation of the manipulator dynamic error at investigated points which take into account inertia characteristics of its operating units. The obtained results allowed correcting the position of the output link at each investigated point of the motion path along the coordinate $z$ (during experiments). Relations (1) were obtained at the following chosen factors: $m l$ $=40.8 \mathrm{~kg} ; v_{\max 1}=10 \mathrm{~mm} / \mathrm{s}, v_{\max 2}=30 \mathrm{~mm} / \mathrm{s}, v_{\max 3}=$ $60 \mathrm{~mm} / \mathrm{s}, v_{\max }=80 \mathrm{~mm} / \mathrm{s}, v_{\max 5}=110 \mathrm{~mm} / \mathrm{s}$.

Fig. 1 shows the empiric relations for the manipulator dynamic error depending on kinetic energy at reference points of the motion path when the manipulator output link is displacing along the motion path at variation of velocities.

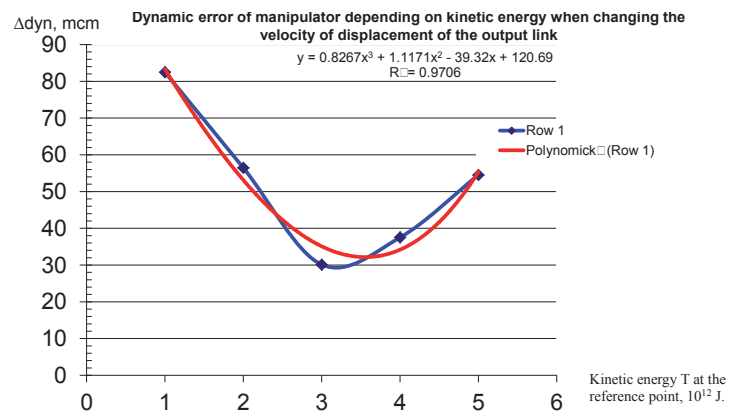

Fig. 1: Dynamic error vs. kinetic energy at reference points of the motion path when changing the velocity of displacement of the manipulator output link.

Fig. 1 shows that when the linear velocity of the 
manipulator output link displacement is increased and, therefore, kinetic energy is increased, the value of dynamic error is decreased. It is stipulated by taking into account the value of the output link deviation from the nominal position based on determining the dynamic error along the coordinate z. Empiric relation of the manipulator output link deviation from the assigned position is non-linear, that is explained by non-uniform distribution of reference points along the motion path.

\section{Results and Discussion}

The performed numerical experiments based on the proposed model of providing the assigned positioning accuracy resulted in determining the deviations of the manipulator output link from the assigned position with account of kinematic and dynamic characteristics of the mechanical system. The total kinetic energy of the system depends on mass, linear and angular velocities, moments of inertia and geometric parameters of the manipulator link. Empiric relation of the manipulator output link deviation from the assigned position is non-linear, that is explained by non-uniform distribution of reference points along the motion path.

\section{Conclusions}

The performed investigations resulted in obtaining experimental data on deviations of the manipulator output link from the nominal position along the axis z. Based on statistical analysis of experimental data, the mean deviations from the nominal position for each reference point of the motion path were determined, the experimental data being obtained by the external sensor of position. Moreover, the mean square deviation from the assigned position was determined for twenty measurements. Results of experiments showed that the value of deviation for the manipulator output link from the nominal position (positioning error) is decreased when the proposed procedure is applied to account the dynamic component of the error based on empiric relations.

Therefore, in order to implement investigations, the procedure was developed to carry out the experimental research of the positioning accuracy for the robot-manipulator output link with account of the dynamic error. The procedure of carrying out the experimental research includes experiment planning, processing and analysis of the obtained experimental data.

The performed experimental investigations of the positioning accuracy for the manipulator output link during its motion path tryout allowed stating that application of this approach with obtaining the empiric relation taking into account the influence of the dynamic component of the error is the efficient means of increasing the manipulator positioning accuracy and, as a consequence, of increasing the quality of the produced units.

\section{Acknowledgments \\ The reported study was partially supported by RFBR, research project No. 13-08-0118 a.}

\section{References}

[1] Turygin Yu.V., Zubkova Yu.V., Maga D. 2012. Investigation of kinematic error in transmission mechanisms of the mechatronic system. Proceedings of the 15th International conference on mechatronics «MECHATRONICS-2012》. Prague, Czech Republic, 351-354.

[2] Poduraev Yu.V. 2007. Mechatronics: methods, application: study guide for university students, 2nd ed. Mashinostroenie, Moscow.

[3] Turygin Yu.V., Zubkova Yu.V. 2013. Experimental investigation of kinematic error influence on positioning accuracy for the output link of the mechatronic system. Intelligent systems in production. N2, 100-104

[4] Turygin Yu.V., Zubkova Yu.V., Gartyanski R. 2014. Assurance of the Electron Beam Positioning Accuracy at Electron Beam Welding. Proceedings of the RAAD, Smolenice Castle, Slovakia, 349-353.

[5] Virgala, I., Frankovský, P., Kenderova, M. (2013). Friction Effect Analysis of a DC Motor. In: American Journal of Mechanical Engineering, 1(1), 1-5.

[6] Živčak, J., Kelemenová, T., Kelemen, M., Maxim, V.: Modelbased approach to development of engineering. In: Acta Mechanica Slovaca. Roč. 17, č. 3 (2013), s. 56-62. - ISSN $1335-2393$

\section{Biographical notes}

Yulia Zubkova, Year of birth - 1980. Now she is the Senior Lecturer at "Mechatronic Systems" Department of Kalashnikov Izhevsk State Technical University (ISTU). She graduated from Kalashnikov Izhevsk State Technical University in 2002. Her professional scientific areas are mechatronics, robotics, automation. The relevant publications are: 1) Turygin Yu.V., Zubkova Yu.V. Dynamic component of positioning error for the output link of the mechatronic system. Vestnik ISTU. 2012. N2. pp. 43-46; 2) Turygin Yu.V., Zubkova Yu.V. Experimental investigation 
Acta Mechanica Slovaca

Journal published by Faculty of Mechanical Engineering - Technical University of Košice

of kinematic error influence on positioning accuracy for the output link of the mechatronic system. Intelligent Systems in Production. 2013. N2. pp. 100-104; 3) Turygin Yu.V., Smirnov V.N., Zubkova Yu.V. The total error of mechatronic module in control model of electron beam positioning process during electron beam welding. Proceedings of 14th International Conference on Mechatronics. Trencianske Teplice, Slovakia, 2011. pp. 89-92; 4) Turygin Yu.V., Zubkova Yu.V., Maga D. Investigation of kinematic error in transmission mechanisms of the mechatronic system. Proceedings of the 15th International Conference on Mechatronics "Mechatronic-2012". Prague, Czech Republic. 2012. pp.351-354.

Yury Turygin, Turygin Yury Vasilievich, DSc in Engineering, Professor. Year of birth - 1951. Now he is the Head of Administration for Master, Post-graduate and DSc courses of Kalashnikov lzhevsk State Technical University (ISTU) and Professor of "Mechatronic Systems" Department of ISTU. He is the member of three Dissertation Councils for DSc theses. Prof. Turygin graduated from Izhevsk Mechanical Institute (now Kalashnikov ISTU) in 1973. His professional scientific areas are investigation and calculation of reliability for complex systems and their elements; maintenance and repair of complex mechanical systems; strength of machine and device parts and machine parts analysis; planning the experiments of units and their components; computer-aided engineering analysis and design; mechatronics and robotics; mechanical engineering (computer-aided manufacturing, machine assembly, press-fit joints). The relevant publications are: 1) Turygin Yu.V., Smirnov V.N., Zubkova Yu.V. Model of electron beam positioning control of electron beam welding process. International Symposium Advances in Mechatronics 2007 (AiM 07), (zech Republic, 2007. ISBN 978-80-7231-314-3; 2) Turygin Yu.V., Zubkova Yu.V., Gartyanski R. Investigation of positioning accuracy for the output link of the mechatronic system. "Mechatronics, automation, control', 2014, N7, pp. 35-41. ISSN 1684-6427.; 3) Platov S., Turygin Yu.V. Railtruck Robotic Spring End Process Operating System. Proceedings of the RAAD 2014, 23rd International Conference on Robotics in Alpe-Adria-Danube Region. Slovakia. pp. 127-132. ISBN 978-80-227-4219-1. 